\title{
Warfarin
}

\section{STEREOCHEMICAL ASPECTS OF ITS METABOLISM AND THE INTERACTION WITH PHENYLBUTAZONE}

\author{
Richard J. Lewis, William F. Trager, Kenneth K. Chan, A. Breckenridge, M. Orme, \\ Malcolm Roland, and William Schary
}

From the Veterans Administration Hospital, the Department of Medicine, School of Medicine, and the Department of Pharmacy, School of Pharmacy of the University of California, San Francisco, California, the University of Washington, Seattle, Washington and the Department of Clinical Pharmacology, Royal Postgraduate Medical School, London

A B S T R A C T An examination of the metabolic fate of the $\mathrm{R}$ and the $\mathrm{S}$ isomers of warfarin revealed that the two isomers were metabolized by different routes. $R$ warfarin was oxidized to 6-hydroxywarfarin and was reduced to the $(\mathrm{R}, \mathrm{S})$ warfarin alcohol. In contrast, $\mathrm{S}$ warfarin was oxidized to 7-hydroxywarfarin and was reduced to the $(\mathrm{S}, \mathrm{S})$ warfarin alcohol. $\mathrm{S}$ warfarin was also oxidized to 6-hydroxywarfarin.

These observations suggested that interactions between warfarin and other drugs might be manifest stereospecifically, i.e., have a different effect on the isomers of warfarin, so a series of experiments were conducted with each isomer of warfarin, before and after phenylbutazone. The plasma clearance of $\mathrm{S}$ warfarin was slowed from 3.1 to $1.1 \%$ per $\mathrm{h}$ in one subject and from 2.3 to $1.6 \%$ per $\mathrm{h}$ in another. In contrast, the clearance of $\mathrm{R}$ warfarin was increased from 1.5 to $3.0 \%$ per $\mathrm{h}$ and from 0.9 to $1.6 \%$ per $h$ in two subjects after phenylbutazone. The rate of clearance of racemic warfarin was unaffected by phenylbutazone; the depression of the rate of clearance of the $\mathrm{S}$ isomer masked the stimulation of the clearance of the $\mathrm{R}$ isomer.

Since $S$ warfarin is five times more potent an anticoagulant than $R$ warfarin, it is concluded that inhibition of the metabolism of $\mathrm{S}$ warfarin provides one mechanism for the augmented anticoagulation which follows phenylbutazone.

Portions of this report appeared in Clin. Res. 20: 409, 1972 and 21: 244, 1973 and were presented to the Western Section, AFCR; Carmel, Calif., 2 February 1973.

Dr. Lewis' current address is 465 North Roxbury Drive, Beverly Hills, Calif. 90210.

Received for publication 29 May 1973 and in revised form 5 November 1973.

The Journal of Clinical Investigation Volume .53 June 1974-1607-1617

\section{INTRODUCTION}

The coumarin anticoagulant warfarin contains an asymmetric center. There are two isomeric forms, the (R) $(+)$-warfarin ( $R$ warfarin) and the $(S)(-)$-warfarin ( $\mathrm{S}$ warfarin) isomers (1). The clinically available formulation is a racemate, a mixture of equal parts of each isomer. The racemic mixture has been the subject of intense investigation in studies of the metabolism of warfarin and in studies of drug interactions between warfarin and other drugs. The metabolites of racemic warfarin in man were previously identified as two oxidized derivatives, 6-hydroxywarfarin and 7-hydroxywarfarin, and two reduced derivatives, the diastereoisomers of warfarin alcohol (designated "alcohol 1" and "alcohol 2") (2). For the most part, previous studies have ignored whatever differences may exist between the $\mathrm{R}$ and $\mathrm{S}$ isomers of warfarin in regard to either their metabolism or their response to interactions with other drugs.

There is ample evidence to indicate that the stereochemical configuration of drugs which possess asymmetric centers is an important determinant of metabolism. Different rates of metabolism have been demonstrated between the isomers of methadone (3), propranolol (4), amphetamine (5), hexobarbital (6), and hydantoins (7).

Three reports suggested that the steric configuration of warfarin might influence its metabolism. The data of Goding and West in rats indicated that the rate of appearance of radioactivity in the urine was more rapid after administration of the $R$ isomer of $\left[{ }^{14} \mathrm{C}\right]$ warfarin than after administration of the $\mathrm{S}$ isomer (8). Breckenridge and L'E Orme reported that $R$ warfarin was cleared from the plasma of rats at a rate nearly twice 
that of the $\mathrm{S}$ isomer (9). Hermodson provided direct evidence of the dependence of metabolic pathways on the configuration of warfarin (10). In a study of the urine of a remarkable patient who was resistant to racemic warfarin, the 7-hydroxywarfarin that was isolated was optically active. This indicated stereospecificity in the formation of the 7-hydroxy metabolite: it was generated exclusively (or primarily) from only one of the isomers of warfarin.

$\mathrm{S}$ warfarin is 5-6 times more potent as an anticoagulant than the $\mathrm{R}$ isomer in both man (11) and the rat $(9,12)$. Thus, the configuration of warfarin greatly influences its pharmacologic effect. This emphasizes the relevance of any relationship that might be established between the configuration and the metabolism of warfarin.

Methods recently developed permit the concentrations of warfarin metabolites as well as unchanged warfarin to be measured specifically. Because of this analytic improvement, the metabolism of the isomers was explored, and the interaction between warfarin and phenylbutazone was reexamined. The data presented in this report suggest that, in addition to differences in potency, the isomers of warfarin differ in regard to their metabolism and differ in regard to their interactions with other drugs.

\section{METHODS}

\section{Metabolism of the isomers}

The isomers of warfarin were gifts of Endo Laboratories, Inc. (Garden City, N. Y.) and Ward Blenkinsop Pharmaceuticals. The optical purity of each isomer was approximately 93-95\%. Racemic warfarin (Coumadin, Endo Laboratories, Inc.) was an equal mixture of the two isomers. The syntheses of the metabolites of warfarin have been described previously (13). The subjects were fully informed. Single oral doses of each isomer were given in separate, paired studies of eight subjects. The same dose of both isomers was administered to a subject. A dose of racemic warfarin was given to four of the subjects. Citrated plasma samples were obtained over the subsequent 3-9 days. Three subjects were given vitamin $K$ during the study; the "prothrombin time" of all samples obtained from the other subjects was measured together, with Simplastin-A (General Diagnostics, Div., Warner-Lambert Pharmaceutical, Morris Plains, N. J.) as a source of thromboplastin and Factor V. It was possible to obtain urine samples from five subjects. In these, urine was collected quantitatively for 7-10 days of each study and pooled.

\section{Studies with phenylbutazone}

The subjects were fully informed healthy male volunteers. For control data, a single oral dose of racemic warfarin was administered, and citrated plasma samples were obtained over the subsequent 4-10 days. Phenylbutazone pretreatment was $100 \mathrm{mg}$ t.i.d. for 10 days, after which the second single dose of warfarin was administered. Phenylbutazone was continued for the remainder of the study. Other subjects were given a single oral dose of an isomer of warfarin before and again after phenylbutazone pretreatment.

\section{Analytical procedure}

All samples of plasma and urine were frozen until analyzed. Each sample was processed in duplicate. A standard of plasma or urine containing a known amount of warfarin, 6-hydroxywarfarin, 7-hydroxywarfarin, warfarin alcohol 1 and warfarin alcohol 2 was processed simultaneously.

Warfarin and the metabolites were extracted from the plasma and urine samples, separated chromatographically, and quantitated fluorometrically.

Extraction. $2 \mathrm{ml}$ of plasma or urine was acidified with $1.0 \mathrm{ml}$ of $1.5 \mathrm{~N} \mathrm{HCl}$ and extracted with $4.0 \mathrm{ml} \mathrm{1,2-di-}$ chloroethane (ethylene dichloride, $\mathrm{EDC}^{1}$ ) in a polypropylene tube by agitation on a horizontal shaker for $10 \mathrm{~min}$. The tube was centrifuged at $10,000 \mathrm{~g}$, the aqueous and solid phases were discarded, and $3.0 \mathrm{ml}$ of the EDC were transferred to a glass tube. While the EDC was evaporating in a stream of $\mathrm{N}_{2}$, the sides of the tube were washed down 3-4 times with $100-200 \mu 1$ of acetone. To the dried residue at the bottom of the tube, $100 \mu 1$ of acetone was added. This was applied quantitatively as a $1.5-\mathrm{cm}$ band on a silica gel-G thin-layer chromatography (TLC) plate, (6061, Eastman Kodak, Rochester, N. Y.). The tube was rinsed an additional two times with acetone, which was added to the spot of application on the TLC plate.

Chromatographic separation. The large spots of application were collected by chromatographing the TLC plates with methanol to a point $3 \mathrm{~cm}$ above the site of application. The plates were examined under shortwave ultraviolet light (Mineralight UVS-12, Ultra-Violet Products, Inc., San Gabriel, Calif.), and the collection with methanol was repeated until all material with blue fluorescence had been collected at the methanol collection front. The TLC plates were cut off $2 \mathrm{~cm}$ below the methanol line. The plates were developed initially in chloroform: ethyl acetate: acetic acid 150:50:1 to a point $10 \mathrm{~cm}$ above the methanol collection line. (Then four discrete bands of blue fluorescence could be differentiated under ultraviolet light: warfarin at $R_{f} 0.61$, alcohol 1 at 0.39 , alcohol 2 at 0.31 , and 6-hydroxywarfarin and 7-hydroxywarfarin overlapping at $R_{f} 0.23$.) The plates were dried, cut off at the level of the methanol collection front, and developed a second time with tertbutanol : benzene: $\mathrm{NH}_{4} \mathrm{OH}$ : water $90: 40: 18: 6$ to a point approximately $15 \mathrm{~cm}$ above the methanol line. By this means, five fluorescent bands were resolved that corresponded to the standard materials: $R_{f} 0.79$ for warfarin, 0.69 for alcohol $1,0.61$ for alcohol $2,0.53$ for 6-hydroxywarfarin, and 0.23 for 7-hydroxywarfarin. The bands were outlined with pencil and cut out, and each was placed in a glass tube. ${ }^{2}$

Quantitation. Each compound was eluted for $20 \mathrm{~min}$ with $1.5 \mathrm{ml}$ of solvent. The solvent was transferred to a

${ }^{1}$ Abbreviations used in this paper: EDC, ethylene dichloride, 1,2-dichloroethane; TLC, thin-layer chromatography; $V_{D}$, volume of distribution.

${ }^{2}$ Usually no fluorescence was detected when normal (blank) plasma was processed, but occasionally material with yellow fluorescence was noted along a second solvent front, at a position between warfarin and alcohol 1 . When normal urine was chromatographed, a background of yellow fluorescence was usually apparent, more intense toward the origin. Discrete bands with yellow or blue fluorescence were observed infrequently. 
clean $10 \times 75-\mathrm{mm}$ flint glass culture tube (Kimble 73500, Kimble Products Div., Owens-Ill., Inc., Toledo, Ohio), and the fluorescence of the solution was measured with a Perkin-Elmer model 203 spectrofluorometer (Perkin-Elmer Corp., Instrument Div., Norwalk, Conn.).

The warfarin, alcohol 1 , and alcohol 2 bands were eluted with acetone, and the fluorescence was measured at $405 \mathrm{~nm}$ with exciting light of $345 \mathrm{~nm}$. The fluorescence of the solution was measured again after the addition of 1 drop $3 \mathrm{~N} \mathrm{HCl}$. The net fluorescence of the sample (the difference between the before-acid and after-acid readings) was compared to the net fluorescence of the standard, and the concentration of the compound was calculated from this ratio. The fluorescent band containing 7-hydroxywarfarin was eluted with $n$-butanol. Then 3 drops of concentrated $\mathrm{HCl}$ were added, the solutions were mixed, and the tube was allowed to stand. After $1 \mathrm{~h}$ the solutions were mixed, and the fluorescence was measured at $365 \mathrm{~nm}$ with an exciting light at $330 \mathrm{~nm}$. The band containing 6-hydroxy warfarin was eluted with methanol and the fluorescence was measured at $390 \mathrm{~nm}$ with an exciting light of $325 \mathrm{~nm}$.

Methodologic evaluation. The relationship between concentration and fluorescence was linear over a range from less than 10 to over $1,000 \mathrm{ng}$ per $\mathrm{ml}$ plasma or urine. Quenching, observed at much higher concentrations, was obviated when indicated by diluting both the sample and the standard with the appropriate solvent. The reproducibility of replicate determinations of more than $85 \%$ of the samples was within $15 \%$ or $15 \mathrm{ng}$ of the average of the two determinations. Bias was evaluated in two experiments in which plasma samples were randomly coded by another (uninvolved) investigator. After the results were calculated, the code was broken. The accuracy in these blinded studies was similar to experiments in which the time the samples were obtained was known both by the laboratory personnel and the investigator.

The fluorescence of a series of normal plasma samples were equivalent to $10-20 \mathrm{ng}$ warfarin, 1-4 $\mathrm{ng}$ alcohol 1, 1-4 ng alcohol 2, and 1-3 ng 7-hydroxywarfarin per ml plasma. Similar results were obtained with plasma obtained from subjects receiving phenylbutazone but not warfarin. Thus phenylbutazone (or its metabolites) did not interfere with the assay. A series of normal urine samples gave fluorescence equivalent to 9-25 $\mathrm{ng}$ warfarin, 0-2 ng alcohol 1, 1-9 ng alcohol 2, 10-180 ng 6-hydroxywarfarin, and 4-11 ng 7-hydroxywarfarin per $\mathrm{ml}$ urine. ${ }^{3}$

The concentrations of phenylbutazone were measured by the method of Jahnchen and Levy (14). The relative amounts of free and protein-bound warfarin were measured in the following manner: $10 \mu \mathrm{g}$ of $\left[{ }^{14} \mathrm{C}\right]$ warfarin (sp act $3.74 \mu \mathrm{Ci}$ per $\mathrm{mg}$ ) were added to each $\mathrm{ml}$ of plasma samples obtained during the control and phenylbutazone studies, and the plasma samples were incubated at $37^{\circ} \mathrm{C}$ for $2 \mathrm{~h}$. (The fraction bound was not altered by addition of this amount of radioactive warfarin.) Aliquots were centrifuged at $400,000 \mathrm{~g}$ for $24 \mathrm{~h}$ at $37^{\circ} \mathrm{C}$ in a modified Beckman L2-65 B centrifuge (Beckman Instruments, Inc., Spinco Div., Palo Alto, Calif.). The radioactivity remaining in the supernate

${ }^{3}$ No data are presented for the 6-hydroxywarfarin in the plasma. Inspection of the TLC plates after development suggested the presence of this metabolite in the samples, but the fluorescence yield from 6-hydroxywarfarin, despite the testing of a number of different solvents, was too inefficient to yield reliable data. The low fluorescence also limited the sensitivity of the determination of 6-hydroxywarfarin in the urine. was measured in a Packard liquid scintillation counter (Packard Instrument Co., Inc., Downers Grove, I1l.). The protein content of the supernate was measured by a modification of the method of Lowry, Rosebrough, Farr, and Randall (15). The results were expressed as a percentage of the radioactivity and protein in the original plasma sample.

\section{RESULTS}

\section{Metabolism of the isomers}

Identical results were obtained with all subjects (Figs. 1 and 2). The plasma data indicated that $S$ warfarin was oxidized to 7-hydroxywarfarin and reduced to alcohol 2 . In contrast, $R$ warfarin was metabolized by reduction, primarily to alcohol 1 (Table I)." These observations were confirmed by measuring the excretion of the metabolites in the urine. In all subjects, the urine data indicated that alcohol 1 was produced from $\mathrm{R}$ warfarin, and that alcohol 2 and 7-hydroxywarfarin were produced from $S$ warfarin (Table II). Analyses of the urine also revealed that both $R$ warfarin and $S$ warfarin were oxidized to 6-hydroxywarfarin in approximately equal amounis.

In the evaluation of the studies of the urine it should be noted that for three subjects the dose of racemic

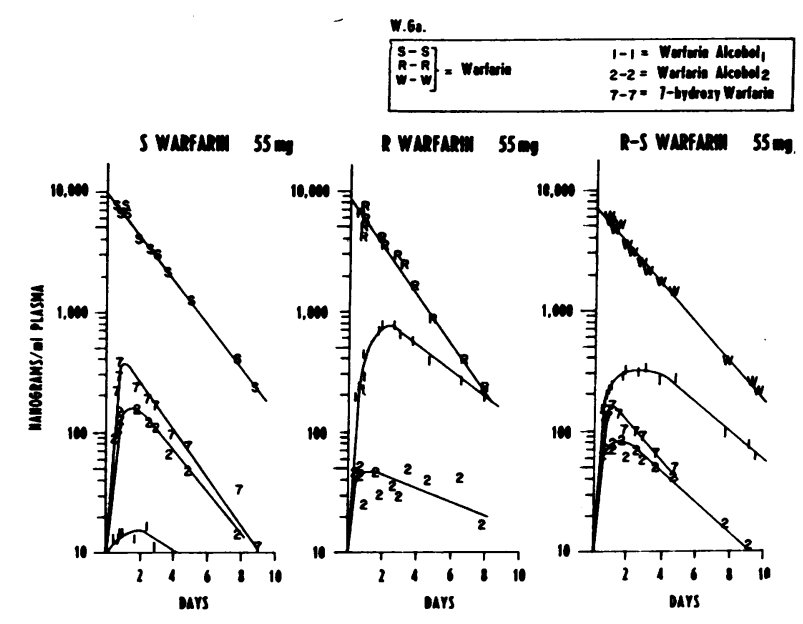

Figure 1 In separate studies, subject W. Ga. was given $55 \mathrm{mg}$ each of $\mathrm{S}$ warfarin, $\mathrm{R}$ warfarin, and the racemate. The racemic mixture contained $27.5 \mathrm{mg}$ of the $R$ isomer and $27.5 \mathrm{mg}$ of the $\mathrm{S}$ isomer of warfarin. 7-hydroxywarfarin and alcohol 2 were generated from $S$ warfarin. Alcohol 1 was a metabolite of $\mathrm{R}$ warfarin. Despite these differences in the pathways of metabolism, the $R$ and $S$ isomers were cleared from the plasma at identical rates in two subjects.

"It was assumed that there were negligible differences in the biologic handling of the isomers of a metabolite, e.g., that 7-hydroxywarfarin produced from $\mathrm{R}$ warfarin would have the same distribution characteristics and the same elimination characteristics as 7-hydroxywarfarin produced from $\mathrm{S}$ warfarin. 


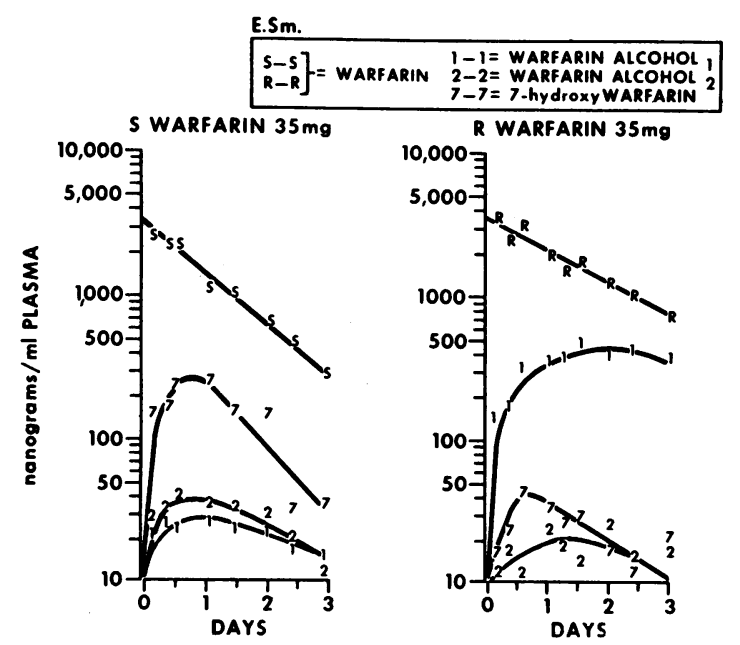

Figure 2 Subject E. Sm. received $35 \mathrm{mg}$ of $\mathrm{S}$ warfarin and $\mathrm{R}$ warfarin. $\mathrm{S}$ warfarin was oxidized to 7-hydroxywarfarin and reduced primarily to warfarin alcohol 2 . $\mathrm{R}$ warfarin was reduced to warfarin alcohol 1 . In six subjects, the plasma clearance of $S$ warfarin was faster than $R$ warfarin. warfarin contained half the amount of each isomer that was given in the studies with the separate isomers. Account was made for most of the $\mathrm{S}$ warfarin administered, although much less of the $\mathrm{R}$ warfarin was recovered. There was no difference in absorption of the isomers, as indicated by the similarity in plasma levels of the isomers. It has been reported that the urine contained $80 \%$ of the radioactivity in a dose of racemic $\left[{ }^{14} \mathrm{C}\right]$ warfarin of two subjects studied (16). Our (unpublished) analysis of those urine samples indicated that (a) $85 \%$ of the radioactivity was extracted by our method and $(b)$ of the extractable radioactivity $90 \%$ was chromatographically identical to warfarin and the four known metabolites. Thus, neither inefficient extraction nor a major, as yet undetected, metabolic pathway would seem responsible for the poor recovery of $\mathrm{R}$ warfarin noted in the present report. It was subsquently noted (17) that the completeness of recovery of radioactivity was proportional to the length of the collection period: 25 days were required to recover $92 \%$ of the radioactivity in the urine. Thus, the $7-10$-day collection

TABLE I

Maximum Concentrations of Warfarin and Metabolites in Plasma

\begin{tabular}{|c|c|c|c|c|c|c|c|c|}
\hline \multirow[b]{2}{*}{ Subject } & \multicolumn{3}{|c|}{ Substance administered } & \multicolumn{2}{|c|}{ Warfarin } & \multirow[b]{2}{*}{ Alrohol 1} & \multirow[b]{2}{*}{ Alcohol 2} & \multirow[b]{2}{*}{ 7-hydroxy } \\
\hline & \multicolumn{2}{|r|}{ Configuration } & $\begin{array}{c}\text { Dose } \\
(0.75 \mathrm{mg} / \mathrm{kg})\end{array}$ & Concn* & $t \frac{1}{2}$ & & & \\
\hline & & & $m g$ & $m g /$ liter & $h$ & $\mu g /$ liter & $\mu g /$ liter & $\mu \mathrm{g} /$ liter \\
\hline \multirow[t]{3}{*}{ R. Co. } & & $\mathrm{R}$ Warfarin & 55 & 6.8 & 46 & 640 & 35 & 28 \\
\hline & & S Wàrfarin & 55 & 7.6 & 22 & 25 & 90 & 580 \\
\hline & & RS Warfarin & 55 & 8.3 & 33 & 250 & 44 & 220 \\
\hline \multirow[t]{3}{*}{ W. Ga. } & & $\mathrm{R}$ Warfarin & 55 & 8.1 & 36 & 790 & 50 & $<10$ \\
\hline & & S Warfarin & 55 & 9.1 & 40 & 15 & 170 & 390 \\
\hline & & RS Warfarin & 55 & 6.6 & 46 & 310 & 82 & 160 \\
\hline \multirow[t]{4}{*}{ L. Ro. } & & $\mathrm{R}$ Warfarin & 60 & 5.8 & 81 & 890 & 42 & 18 \\
\hline & & Warfarin & 60 & 6.7 & 33 & 38 & 86 & 370 \\
\hline & (1) & RS Warfarin & 60 & 5.6 & 49 & 300 & 36 & 140 \\
\hline & (2) & RS Warfarin & 60 & 5.5 & 49 & 300 & 58 & 180 \\
\hline \multirow[t]{3}{*}{ W. Tr. } & & $\mathrm{R}$ Warfarin & 58 & 8.9 & 40 & 800 & 23 & 35 \\
\hline & & S Warfarin & 58 & 10.2 & 41 & 28 & 130 & 1050 \\
\hline & & RS Warfarin & $116 \ddagger$ & 14.1 & 42 & 1300 & 180 & 1100 \\
\hline \multirow[t]{2}{*}{ R. Le. } & & $\mathrm{R}$ Warfarin & $35 \S$ & 4.7 & 45 & 300 & 23 & 33 \\
\hline & & S Warfarin & 35 & 5.3 & 31 & $<10$ & 80 & 180 \\
\hline \multirow[t]{2}{*}{ A. Me. } & & $\mathrm{R}$ Warfarin & $43 \S$ & 3.5 & 43 & 470 & 28 & 80 \\
\hline & & Warfarin & 43 & 4.0 & 18 & 35 & 58 & 540 \\
\hline \multirow[t]{2}{*}{ T. O'D. } & & Warfarin & $48 \S$ & 4.9 . & 40 & 500 & 30 & 35 \\
\hline & & Warfarin & 48 & 5.1 & 21 & 65 & 56 & 480 \\
\hline \multirow[t]{2}{*}{ E. Sm. } & & Warfarin & $35 \S$ & 3.6 & 33 & 420 & 23 & 46 \\
\hline & & Warfarin & 35 & 3.3 & 21 & 28 & 42 & 380 \\
\hline
\end{tabular}

* The value was obtained by back-extrapolation of the warfarin plasma disappearance slope to zero time.

$\ddagger$ Dose was $1.5 \mathrm{mg} / \mathrm{kg}$ body wt.

$\S$ Dose was $0.5 \mathrm{mg} / \mathrm{kg}$ body wt. 
TABLE II

Recovery of Warfarin and Metabolites in Urine; Control Studies

\begin{tabular}{|c|c|c|c|c|c|c|c|c|c|}
\hline \multirow[b]{2}{*}{ Subject } & \multicolumn{2}{|c|}{ Substance administered } & \multicolumn{7}{|c|}{ Compound recovered } \\
\hline & Configuration & Dose & Warfarin & Alcohol 1 & Alcohol 2 & 7-Hydroxy & 6-Hydroxy* & Total & $\%$ of Dose \\
\hline \multirow[t]{3}{*}{ R. Co. } & R Warfarin & $55 \ddagger$ & 0.5 & 4.0 & 0.7 & 2.4 & 7.7 & 15.3 & 29 \\
\hline & S Warfarin & 55 & 0.5 & 0.2 & 2.4 & 27.0 & 7.4 & 37.5 & 68 \\
\hline & RS Warfarin & 55 & 0.6 & 2.3 & 1.7 & 16.1 & 9.7 & 30.4 & 55 \\
\hline \multirow[t]{3}{*}{ W. Ga. } & $\mathrm{R}$ Warfarin & 55 & 0.9 & 3.4 & 0.5 & 1.1 & 6.4 & 12.3 & 22 \\
\hline & S Warfarin & 55 & 1.1 & $-\S$ & 3.9 & 18.9 & 7.9 & 31.8 & 58 \\
\hline & RS Warfarin & 55 & 0.8 & 2.3 & 1.8 & 7.7 & 5.4 & 18.0 & 33 \\
\hline \multirow[t]{4}{*}{ L. Ro. } & $\mathrm{R}$ Warfarin & 60 & 0.7 & 8.8 & 0.9 & 1.7 & 6.7 & 18.8 & 31 \\
\hline & S Warfarin & 60 & 0.7 & 0.6 & 3.5 & 30.9 & 7.2 & 42.9 & 71 \\
\hline & (1) RS Warfarin & 60 & 0.8 & 4.7 & 1.7 & 15.6 & 7.9 & 30.7 & 51 \\
\hline & (2) RS Warfarin & 60 & 0.7 & 4.6 & 1.7 & 16.6 & 8.7 & 32.3 & 54 \\
\hline \multirow[t]{3}{*}{ W. Tr. } & $\mathrm{R}$ Warfarin & 58 & 0.9 & 3.5 & 0.5 & 1.8 & 5.0 & 11.7 & 20 \\
\hline & S Warfarin & 58 & 0.9 & 0.2 & 2.9 & 17.5 & 6.4 & 27.9 & 48 \\
\hline & RS Warfarin & 1.16 & 3.1 & 4.0 & 4.4 & 19.7 & 21.7 & 52.9 & 46 \\
\hline \multirow[t]{2}{*}{ R. Le. } & $\mathrm{R}$ Warfarin & 35 & 0.4 & 1.8 & 0.3 & 1.2 & 4.0 & 7.8 & 23 \\
\hline & S Warfarin & 35 & 0.5 & 0.2 & 2.0 & 15.0 & 4.9 & 22.6 & 65 \\
\hline
\end{tabular}

* The values for 6-hydroxywarfarin should be regarded only as approximations due to the variably high values observed with a series of normal urine samples: up to $0.2 \mathrm{mg}$ per liter of apparent "6-hydroxywarfarin."

$\ddagger$ All the values given are in $\mathrm{mg}$.

$\S$ A fluorescent contaminating compound in this urine pool could not be separated chromatographically from alcohol ${ }_{1}$ and precluded measurement of alcohol ${ }_{1}$.

in the present report probably was not long enough to obtain complete recovery.

In all but two subjects, the clearance of $S$ warfarin was faster than the $R$ isomer (Table $I$ ). In no subject was $\mathrm{S}$ warfarin eliminated more slowly than the $\mathrm{R}$ isomer. These observations in man are the reverse of the situation found in the rat, where $S$ warfarin is the isomer more slowly metabolized $(8,9)$.

The prothrombin time response from $\mathrm{S}$ warfarin was greater than the response from $R$ warfarin in all five subjects in which this parameter was evaluated. Representative studies are depicted in Fig. 3.

\section{Studies with phenylbutazone}

Phenylbutazone levels. After pretreatment the concentration of phenylbutazone in plasma samples obtained immediately before or during the warfarin study averaged $76 \pm 7$ ( $\bar{x} \pm 1 \mathrm{SD}) \mathrm{mg}$ per liter plasma.

Protein binding of warfarin. Little free warfarin was detected in the supernate when normal plasma was studied. The warfarin radioactivity in the $400,000 \mathrm{~g}$ supernate was only $0.4 \%$ of that contained in the original plasma samples. The actual free warfarin concentration might have been even less, since the supernate also contained $0.3 \%$ of the "protein" of the original plasma sample. It is not known whether this "protein" repre- sented nonspecific reacting material or was albumin remaining in the supernate despite the $400,000 \mathrm{~g}$ sedimentary forces. In the samples obtained after phenylbutazone (three subjects), the apparent free warfarin concentration was increased to $0.8,1.1$, and $1.2 \%$ of the total warfarin. Since these plasma samples were obtained from in vivo experiments, no attempt was made to establish the association constants for the binding with albumin.

Response of racemic warfarin to phenylbutazone. The prothrombin time response to a single dose of racemic warfarin was much greater after phenylbutazone than
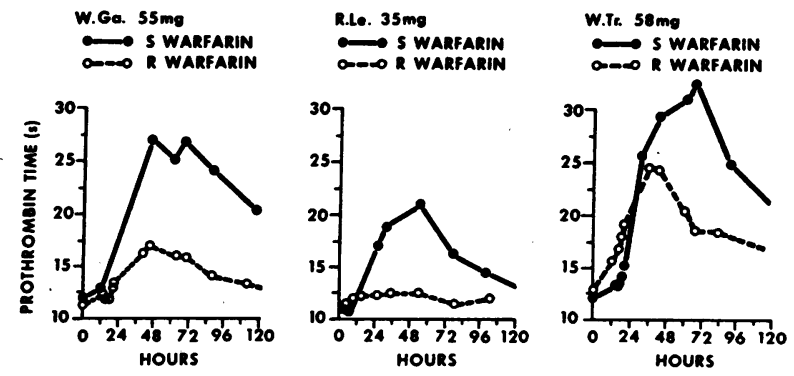

FIGURE 3 The anticoagulant effect of $S$ warfarin was several times that produced by an equal dose of the $R$ isomer in all subjects studied. 

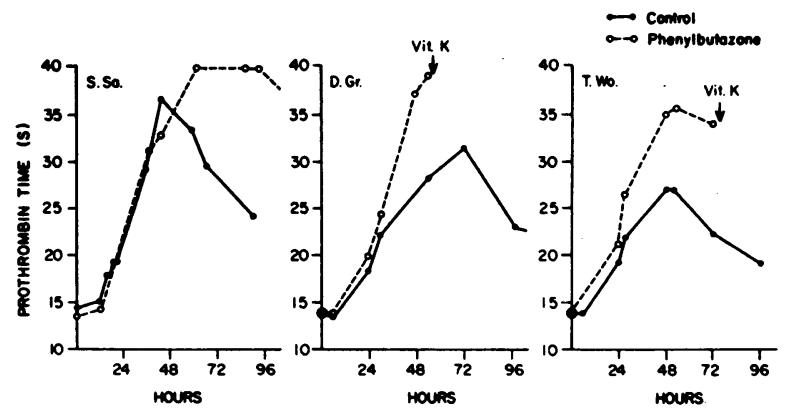

FIGURE 4 The prothrombin time responses were monitored in three subjects who were given single oral doses of warfarin before and again after 10 days of pretreatment with phenylbutazone. In each subject the anticoagulant action was augmented after phenylbutazone, and two of the subjects required vitamin $\mathrm{K}_{\mathbf{1}}$.

in the control study (Fig. 4). In contrast to previous reports, phenylbutazone did not increase the fractional rate of clearance of racemic warfarin from plasma (Fig. $5)$. In two subjects the elimination after phenylbutazone was minimally slower than in the control study. Despite the lack of effect of phenylbutazone on the fractional clearance, three changes in the metabolism of the racemic mixture of warfarin were consistently observed (Fig. $6)$ : (a) the concentration of 7-hydroxywarfarin was lower than in the control study; $(b)$ the concentration of warfarin alcohol 2 was higher, and the time to reach the maximum level was delayed; $(c)$ there was a slightly higher concentration of warfarin alcohol 1 and the peak level was reached earlier. These data are summarized in Table III.

Response of warfarin isomers to phenylbutazone. After phenylbutazone the elimination of $\mathrm{S}$ warfarin was slowed from 2.3 to $1.6 \%$ per $\mathrm{h}$ in one subject (Fig. 7) and from 3.1 to $1.1 \%$ per $\mathrm{h}$ in another. An opposite

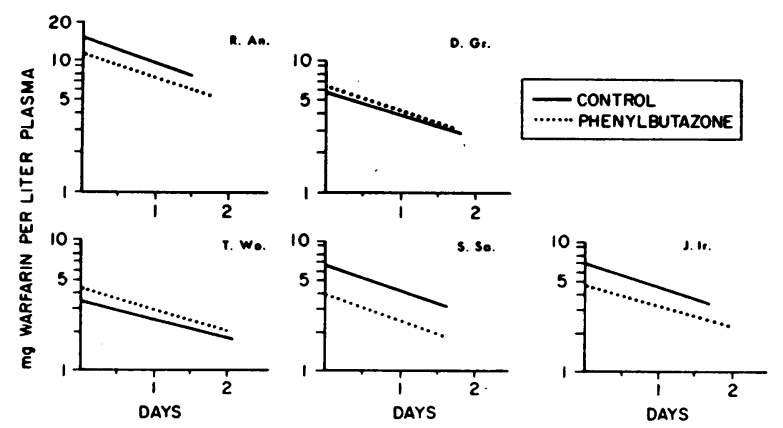

FIgURE 5 The elimination of single oral doses of racemic warfarin from the plasma was unchanged after phenylbutazone. In these studies, which were conducted for 4-10 days, the plasma $t \frac{1}{2}$ of racemic warfarin is indicated by the length of the lines. There were no consistent changes detectable in the ratio: fractional dose absorbed/apparent $V_{D}$ after phenylbutazone. effect on the elimination of $R$ warfarin was noted: the elimination of $\mathrm{R}$ warfarin was accelerated from 1.5 to $3.0 \%$ per $\mathrm{h}$ in one subject and from 0.9 to $1.6 \%$ per $\mathrm{h}$ in another (Table III). Despite the increased rate of clearance, the anticoagulant activity of $R$ warfarin was increased in one subject after phenylbutazone.

\section{DISCUSSION}

The $\mathrm{R}$ and $\mathrm{S}$ isomers of warfarin appeared to be different drugs. First, the isomers differed in their potency: $\mathrm{S}$ warfarin was several times more effective an anticoagulant than $\mathrm{R}$ warfarin. Second, the isomers differed in their metabolism: $\mathrm{R}$ warfarin was metabolized to 6-hydroxywarfarin and alcohol 1, whereas $\mathrm{S}$ warfarin was metabolized to 7-hydroxywarfarin, alcohol 2, and 6-hydroxywarfarin. Third, the isomers differed in their interaction with other drugs: the clearance of $\mathrm{S}$ warfarin was inhibited by phenylbutazone, whereas that of $\mathrm{R}$ warfarin was stimulated. These observations indicate the significance of stereochemical considerations in regard to the metabolism of warfarin and suggest the importance of such considerations in the evaluation of biologically active isomers of other drugs.

\section{Metabolism of the isomers}

Metabolism by reduction. When the nonsymmetrically substituted ketone group of a drug is reduced, an asymmetric center is created. When the reduction is mediated enzymatically, the reaction is stereoselective (18), and optically active metabolites are produced, e.g., the reduced metabolite of acetohexamide (19). Gener-

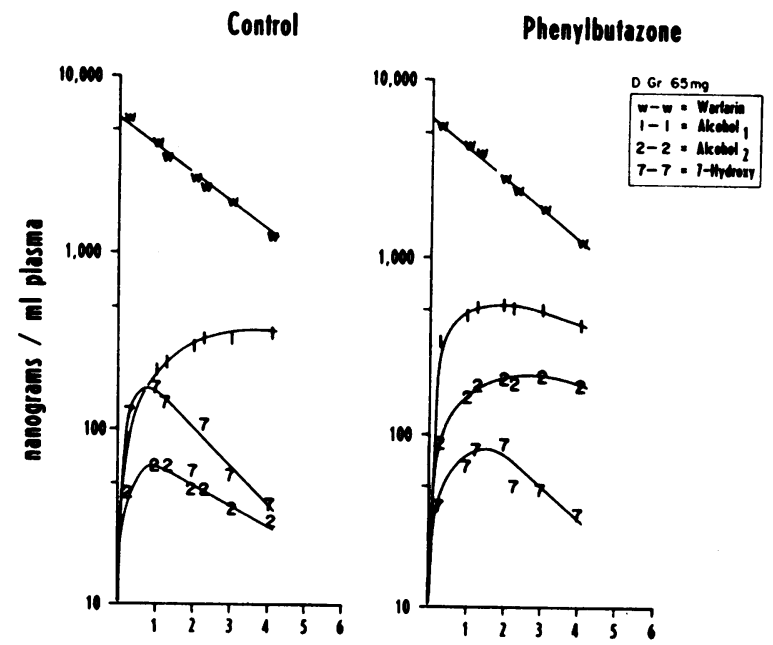

Figure 6 Three consistent changes in the plasma levels of warfarin metabolites were observed in all subjects after phenylbutazone: lower concentrations of 7-hydroxywarfarin, higher and earlier peak levels of warfarin alcohol 1 (the RS alcohol), and higher but later peaks for alcohol 2 (the SS alcohol). 
TABLE III

Effect of Phenylbutazone Pretreatment on Plasma Warfarin $\frac{1}{2}$ and the Peak Appearance Times and Maximum Concentrations of Warfarin Metabolites

\begin{tabular}{|c|c|c|c|c|c|c|c|c|c|}
\hline \multirow[b]{2}{*}{ Subject } & \multirow[b]{2}{*}{ Compound } & \multirow[b]{2}{*}{ Study } & \multirow[b]{2}{*}{$\underset{t}{\text { Warfarin }}$} & \multicolumn{2}{|c|}{ Alcohol 1} & \multicolumn{2}{|c|}{ Alcohol 2} & \multicolumn{2}{|c|}{ 7-Hydroxy } \\
\hline & & & & $\begin{array}{l}\text { Max. } \\
\text { concn }\end{array}$ & $\begin{array}{l}\text { Peak } \\
\text { time }\end{array}$ & $\begin{array}{l}\text { Max. } \\
\text { concn }\end{array}$ & $\begin{array}{c}\text { Peak } \\
\text { timef }\end{array}$ & $\begin{array}{l}\text { Max. } \\
\text { concn }\end{array}$ & $\begin{array}{c}\text { Peak } \\
\text { time }\end{array}$ \\
\hline & & & $h$ & $n g / m l$ & $h$ & $n g / m l$ & $h$ & $n g / m l$ & $h$ \\
\hline \multirow[t]{2}{*}{ D. Gr. } & \multirow{2}{*}{$\begin{array}{l}\text { RS warfarin } \\
\text { RS warfarin }\end{array}$} & Control & 45 & 350 & 96 & 68 & 18 & 200 & 16 \\
\hline & & Phenylbutazone & 41 & 480 & 38 & 180 & 48 & 85 & 24 \\
\hline \multirow[t]{2}{*}{ J. Ir. } & \multirow{2}{*}{$\begin{array}{l}\text { RS warfarin } \\
\text { RS warfarin }\end{array}$} & Control & 40 & 240 & 56 & 53 & 20 & 170 & 22 \\
\hline & & Phenylbutazone & 49 & 280 & 56 & 120 & 60 & 70 & 32 \\
\hline \multirow[t]{2}{*}{ S. Sa. } & \multirow{2}{*}{$\begin{array}{l}\text { RS warfarin } \\
\text { RS warfarin }\end{array}$} & Control & 39 & 265 & 60 & 44 & 22 & 170 & 24 \\
\hline & & Phenylbutazone & 40 & 230 & 48 & 90 & 36 & 70 & 30 \\
\hline \multirow[t]{2}{*}{ T. Wo. } & \multirow{2}{*}{$\begin{array}{l}\text { RS warfarin } \\
\text { RS warfarin }\end{array}$} & Control & 52 & 265 & 72 & 54 & 30 & 270 & 30 \\
\hline & & Phenylbutazone & 47 & 350 & 38 & 100 & 52 & 84 & 20 \\
\hline \multirow[t]{4}{*}{ R. Le. } & $\mathrm{R}$ warfarin & Control & 45 & 300 & 72 & * & * & * & $*$ \\
\hline & $\mathrm{R}$ warfarin & Phenylbutazone & 24 & 210 & 40 & $*$ & $*$ & $*$ & $*$ \\
\hline & $\mathrm{S}$ warfarin & Control & 31 & $*$ & $*$ & 75 & 18 & 180 & 24 \\
\hline & $\mathrm{S}$ warfarin & Phenylbutazone & 44 & $*$ & $*$ & 210 & 54 & 98 & 33 \\
\hline \multirow[t]{2}{*}{ L. Ro. } & warfarin & Control & 81 & 890 & 104 & * & * & * & * \\
\hline & $\mathrm{R}$ warfarin & Phenylbutazone & 45 & 690 & 60 & * & $*$ & $*$ & $*$ \\
\hline \multirow[t]{2}{*}{ R. Co. } & $\mathrm{S}$ warfarin & Control & 22 & $*$ & $*$ & 90 & 22 & 580 & 20 \\
\hline & $\mathrm{S}$ warfarin & Phenylbutazone & 62 & $*$ & $*$ & 245 & 58 & 82 & 46 \\
\hline
\end{tabular}

* Negligible amounts of this metabolite are produced from the indicated isomer of warfarin.

$\ddagger$ Mean paired difference of peak time in control vs. phenylbutazone studies significant at $P \leq 0.02$ level (by Student's $t$ test).

ally, ketones are reduced enzymatically in the same stereochemical sense. Where the configuration of the product is known, the reduced metabolite usually has the $S$ configuration (20).

The biologic reduction of the ketone group of warfarin was similar. In a previous investigation of the absolute configuration of the four warfarin alcohols (21), it was demonstrated that synthetically produced alcohol 1 had the $(R, S)$ and $(S, R)$ configurations. Since the present studies indicated that alcohol 1 was generated from $R$ warfarin, the natural enantiomer of alcohol 1 must have the $(R, S)$ configuration. The absolute configuration of the natural enantiomer of alcohol 2 was deduced in the same manner: warfarin alcohol 2 produced synthetically was shown to have the $(S, S)$ and $(R, R)$ configurations (21). Since alcohol 2 was generated in vivo mainly from reduction of $S$ warfarin, the natural enantiomer of warfarin alcohol 2 had, primarily, the $(S, S)$ configuration. Thus, like other ketones whose enzymatic reductions create asymmetric centers, the ketone group of both isomers of warfarin was reduced by the same stereochemical path to the $\mathrm{S}$ configuration. The reduction produced two metabolites: the (RS) alcohol from $R$ warfarin and the (SS) alcohol from $\mathrm{S}$ warfarin. Similar results have recently been reported by Hewick and McEwen (22).

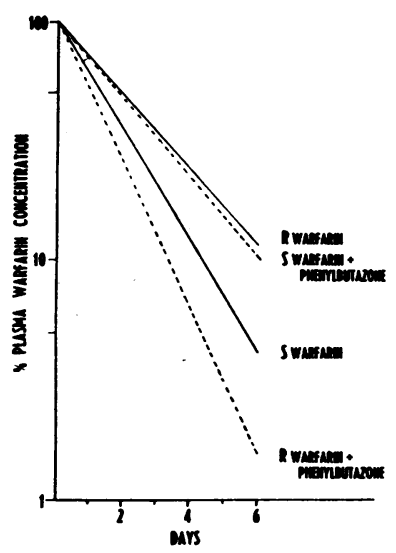

FIGURE 7 Single oral doses of each of the isomers of warfarin were administered before and again after phenylbutazone pretreatment. The concentrations of the isomers are depicted in terms of percent of the extrapolated initial plasma level. Phenylbutazone delayed the rate of clearance of the potent $\mathrm{S}$ warfarin isomer but accelerated the rate of clearance of the weak $R$ warfarin isomer. 
Metabolism by oxidation. Isomers of a drug may be metabolized by oxidation by completely different routes. For example, only $d$-amphetamine is oxidized; the $l$-isomer is not (23). The $d$-isomer of glutethimide is oxidized exclusively in the aromatic ring, whereas the $l$-isomer is oxidized only on the aliphatic side chain of the molecule (24). The stereochemical configuration of a drug may also determine the configuration of its metabolite: when $\mathrm{S}$ pentobarbital is oxidized, the metabolite has primarily the $\mathrm{R}$ configuration at the new asymmetric center, but the oxidation of $R$ pentobarbital produces both $\mathrm{R}$ and $\mathrm{S}$ configurations at the new asymmetric center $(25,26)$. Similar stereochemical requirements were found for the oxidative metabolism of warfarin. Only the $\mathrm{S}$ isomer was oxidized in the 7-position, although both isomers served as substrate for oxidation in the 6-position. The mechanisms responsible for such steric specificity are incompletely understood.

Since the warfarin alcohols have only moderate anticoagulant activity (27) and the hydroxylated metabolites have negligible activity, the differences in metabolism between the isomers do not provide adequate explanation for the fact that $S$ warfarin is several times more potent an anticoagulant than $\mathrm{R}$ warfarin. At present, there are no data to explain the isomeric difference in potency.

\section{Warfarin-phenylbutazone interaction}

When phenylbutazone is administered with other drugs, a diversity of effects is observed on drug metabolism, excretion, and protein binding. The metabolism of drugs has been retarded $(28,29)$, enhanced $(30)$, or both (31) after phenylbutazone. Several effects on renal function have been produced by phenylbutazone or its analogues, including inhibition of tubular reabsorption or tubular secretion (32). Drug-interactions at the renal level have assumed clinical significance: after phenylbutazone, impaired excretion of an active metabolite augmented the hypoglycemic effect of acetohexamide (33).

The mechanism of interaction between phenylbutazone and warfarin has been ascribed to interference in warfarin-albumin binding. Warfarin has a high affinity to albumin, and only small amounts are present as unbound drug (11). It is generally assumed that only the free drug is liable to metabolism. In in vitro systems, phenylbutazone interferes with the binding of many drugs to albumin, and markedly increases the concentration of free warfarin (34). These data supported the suggestion that phenylbutazone augmented warfarin anticoagulation by a displacement mechanism (35). By this means, increased amounts of free warfarin were made available to exert an increased pharmacologic effect and the increase in free drug was reportedly manifest also by an increased rate of metabolism of warfarin $(35,36)$. However, the analytic methods were not specific for warfarin.

The data presented in this report indicate that the interaction between warfarin and phenylbutazone is more subtle and more complex. Phenylbutazone pretreatment failed to affect the clearance of racemic warfarin from plasma. Nevertheless, major, consistent alterations in the plasma levels of the metabolites of warfarin were observed. The concentration of the $(R, S)$ alcohol 1 was increased, the concentration of the (S,S) alcohol 2 was increased, and the concentration of 7-hydroxywarfarin was decreased. ${ }^{5}$

Several mechanisms for these changes after phenylbutazone were considered: $(a)$ alterations in the apparent volume of distribution ( $\mathrm{V}_{\mathrm{D}}$ ) of a metabolite, $(b)$ alterations in its rate of excretion, $(c)$ alterations in its rate of production, or $(d)$ an entirely new pathway of handling of a metabolite. The increased concentration of $(\mathrm{S}, \mathrm{S})$ alcohol 2 and $(\mathrm{R}, \mathrm{S})$ alcohol 1 were not likely due to a reduction in $V_{D}$ of the highly albumin-bound warfarin alcohols (11), since an effect of phenylbutazone would tend to increase the $V_{D}$. In the analysis of substrate-product plasma curves, the time required to achieve peak levels of a product is generally felt to reflect the rate of elimination of the product; viz., a product (metabolite) slowly eliminated would require a long time until peak plasma levels were achieved. As is noted in Fig. 5 and indicated in detail in Table III, the time to reach peak levels of $(\mathrm{S}, \mathrm{S})$ alcohol 2 was significantly longer, delayed after phenylbutazone. This implied that the increased levels of $(\mathrm{S}, \mathrm{S})$ alcohol 2 after phenylbutazone were due to a slowing of the rate of elimination of $(\mathrm{S}, \mathrm{S})$ alcohol 2. Examination of Table III suggests that the peak levels of the $(R, S)$ alcohol 1 were achieved generally earlier (albeit not significantly) after phenylbutazone than in the control studies. This implies that phenylbutazone may have accelerated the rate of elimination of alcohol 1. This would have lowered the plasma concentration. Thus, delayed elimination was an unlikely cause of the higher levels of the (R,S) alcohol 1 . It remained possible that the increased levels of $(R, S)$ alcohol were due to an increased rate of production. Since $(\mathrm{R}, \mathrm{S})$ alcohol 1 was produced from $\mathrm{R}$ warfarin, an increased rate of production of (R,S) alcohol 1 should be manifest by an acceleration in the rate of clearance of $R$ warfarin after phenylbutazone.

A marked, consistent reduction in the plasma levels

\footnotetext{
${ }^{5}$ It is important to note that the data described in the present study pertain to a single-dose warfarin, multipledose phenylbutazone regimen. At this stage it is difficult to predict the precise changes in the isomeric composition of $\mathrm{R}$ and $\mathrm{S}$ warfarin, or the levels of bound and unbound warfarin in plasma, that would result when both warfarin and phenylbutazone are concomitantly administered on a multiple-dose basis.
} 
of 7-hydroxywarfarin was observed after phenylbutazone. This could have been produced by an increase in the $V_{D}$ although 7-hydroxywarfarin is poorly bound to albumin (11) and may be less liable to displacement by phenylbutazone. The possibility could not be excluded. It seemed unlikely that the decreased level of 7-hydroxywarfarin were due to an increase in rate of excretion (with earlier peak concentrations) because the time to reach maximum concentrations was, generally, slower after phenylbutazone than in the control studies (Table III). Although it is possible that phenylbutazone opened unknown elimination pathways (such as further metabolism of 7-hydroxywarfarin to an undescribed metabolite), this hypothesis was not readily testable. Therefore, our analysis considered that the rate of production of 7-hydroxywarfarin was inhibited by phenylbutazone. Since 7-hydroxywarfarin was the major metabolite produced and produced solely from $\mathrm{S}$ warfarin, this hypothesis was testable: it should be manifest by a slowing in the rate of clearance of $S$ warfarin after phenylbutazone.

Accordingly, experiments were performed with separate isomers of warfarin, before and after pretreatment with phenylbutazone. The results of these experiments with the separate isomers of warfarin seemed to confirm the interpretation of the data from the experiments with racemic warfarin. The plasma $t \frac{1}{2}$ of $S$ warfarin was slowed after phenylbutazone: from 31 to $44 \mathrm{~h}$, and from 22 to $62 \mathrm{~h}$. In contrast, the plasma $\mathrm{t} \xi$ of $\mathrm{R}$ warfarin was accelerated after phenylbutazone, from 45 to $24 \mathrm{~h}$ and from 81 to $45 \mathrm{~h}$ (Table III).

The divergent response of the two isomers of warfarin to the interaction with phenylbutazone appears to be without precedent. The impairment in the metabolism of the potent $\mathrm{S}$ isomer provides a mechanism by which the anticoagulant effect would be augmented.

Accumulation of active warfarin metabolites is an unlikely mechanism for the augmentation of anticoagulation. We have previously indicated that the $(R, S)$ and $(\mathrm{S}, \mathrm{S})$ warfarin alcohols possess some, but only limited anticoagulant activity (27). The plasma levels of the warfarin alcohols after phenylbutazone are inadequate to account for the augmentation in anticoagulation. Nevertheless, the concentrations of these active metabolites at the anticoagulant receptor site and the potential effect of phenylbutazone at the receptor site remain unexplored.

Interference with albumin binding may be of importance in the augmentation of anticoagulation. However, for several reasons, caution should be used when clinical significance is attached to in vitro experiments, in which warfarin is displaced from albumin by another drug, when data are obtained exclusively in vitro. First, when the displacement of warfarin by another drug is produced in vitro, there is no means by which the unbound warfarin may distribute into other compartments or be taken up by other (tissue) proteins. Displacement in vitro would therefore indicate misleadingly high levels of free drug. This is clearly demonstrated by the contrast between previous reports that, after phenylbutazone, as much as $30 \%$ of warfarin was in the free form in in vitro experiments (34); whereas, our limited data, when samples were obtained in vivo, suggested that the levels of free warfarin were much lower: only $1 \%$ of the drug was in the free form after phenylbutazone. Second, if displacement from albumin is the sole mechanism of a drug interaction, it would seem logical to expect that the displacement in vitro be manifest also by more rapid metabolism and elimination in vivo. However, confirmation by accelerated plasma clearance in vivo is not invariably made. For example, clofibrate produced significant displacement of warfarin from albumin in vitro (34), but the plasma clearance of warfarin is unchanged after clofibrate (37). Similarly, there is no change in the clearance of (racemic) warfarin after phenylbutazone. Third, our data would seem to demand an additional hypothesis, since $\mathrm{S}$ warfarin was metabolized more slowly after phenylbutazone. Did phenylbutazone displace $S$ warfarin from tissue proteins (the sites of metabolism) as well as from albumin? If so, it seems possible that phenylbutazone, or other displacing drugs, might also alter the binding of warfarin to other tissues, specifically, the sites for pharmacologic effect. With displacing drugs a gamut of anticoagulant responses thus could be anticipated, depending on the degree to which the displacing agent altered tissue binding at receptor sites of pharmacologic effect.

Finally, we would like to emphasize the disturbing limitation of the information obtainable from the measurements of unmetabolized warfarin in plasma. Despite the drastic alterations of phenylbutazone on the metabolism of warfarin, changes in the clearance of the racemic mixture were undetectable: inhibition of the clearance of the potent $\mathrm{S}$ warfarin isomer was masked by stimulation of the clearance of the weak $\mathrm{R}$ warfarin isomer. As noted, studies with the isomers of many drugs have indicated significant metabolic differences between the isomers. It does not seem unreasonable to anticipate that, like warfarin, drug interactions also might be stereochemically dependent. This kind of drug interaction would alter the isomeric composition of the drug in the plasma without changing the total concentration of the racemic mixture. When two isomers differ significantly in pharmacologic potency, such a "masked" change in isomeric composition would assume clinical significance. 


\section{ACKNOWLEDGMENTS}

The authors are grateful for the competent technical assistance of Ms. L. Maritta Carlstrom, Miss Geraldine FitzGerald, and Ms. Helen Rushmer. Mr. Terry Wood participated through a work-study program grant. The authors appreciate the secretarial efforts of Ms. Mary Moser and Ms. Susan Herzig.

This work was performed as a Veterans Administration Clinical Investigator with a Grant-in-Aid of the American Heart Association supported by the Santa Barbara and San Luis Obispo counties chapters (R. J. Lewis), with University of California-Academic Senate grants and GM16496 (W. F. Trager and M. Roland), and with a grant from the Medical Research Council (A. Breckenridge).

\section{REFERENCES}

1. West, B. D., S. Preis, C. H. Schroeder, and K. P. Link. 1961. Studies on the 4-hydroxycoumarins. XVII. The resolution and absolute configuration of warfarin. J. Am. Chem. Soc. 83: 2676.

2. Lewis, R. J., and W. F. Trager. 1970. Warfarin metabolism in man: identification of metabolites in urine. J. Clin. Invest. 49 : 907.

3. Elison, C., H. W. Elliot, M. Look, and H. Rappoport. 1963. Some aspects of the fate and relationship of the n-methyl group of morphine to its pharmacological activity. J. Med. Chem. 6: 237.

4. George, C. F., T. Fenyvesi, M. E. Connolly, and C. T. Dollery. 1972. Pharmacokinetics of dextro-, laevoand racemic propranolol in man. Eur. J. Clin. Pharmacol. $4: 74$.

5. Debackere, M., and A. M. Massart-Lëen. 1965. Identification and metabolism of amphetamine in some domestic animals. Arch. Int. Pharmacodyn. Ther. 155: 459.

6. Furner, R. L., J. S. McCarthy, R. E. Stitzel, and M. W. Anders. 1969. Stereoselective metabolism of the enantiomers of hexobarbital. J. Pharmacol. Exp. Ther. 169: 153.

7. Smith, J. A., W. J. Waddell, and T. C. Butler. 1963. Demethylation of $n$-methyl derivatives of barbituric acid, hydantoin, and 2,4-oxazolidinedione by rat liver microsomes. Life Sci. 2: 486.

8. Goding, L. A., and B. D. West. 1969. Synthesis and relative urinary excretion rates of the enantiomers of warfarin-4- ${ }^{14} \mathrm{C}$ and phenprocoumon-2- ${ }^{14} \mathrm{C}$. J. Med.Chem. $12: 517$.

9. Breckenridge, A., and M. L'E Orme. 1972. The plasma half lives and the pharmacological effect of the enantiomers of warfarin in rats. Life Sci. 11 (Pt. 2): 337.

10. Hermodson, M. A. 1968. Biochemical studies on warfarin. Doctoral Thesis. University of Wisconsin, Madison.

11. O'Reilly, R. A. 1971. Interaction of several coumarin compounds with human and canine plasma albumin. Mol. Pharmacol. $7: 209$.

12. Elbe, J. N., B. D. West, and K. P. Link. 1966. A comparison of the isomers of warfarin. Biochem. Pharmacol. 15 : 1003.

13. Trager, W. F., R. J. Lewis, and W. A. Garland. 1970. Mass spectral analysis in the identification of human metabolites of warfarin. J. Med. Chem. 13: 1196.
14. Jähnchen, E., and G. Levy. 1972. Determination of phenylbutazone in plasma. Clin. Chem. 18: 984.

15. Lowry, O. H., N. J. Rosebrough, A. L. Farr, and R. J. Randall. 1951. Protein measurement with the Folin phenol reagent. J. Biol. Chem. 193: 265.

16. Breckenridge, A., M. L'E Orme, S. Thorgeirsson, D. S. Davies, and R. V. Brooks. 1971. Drug interactions with warfarin: studies with dichloralphenazone, chloral hydrate and phenazone (anti-pyrine). Clin. Sci. (Oxf.). 40: 351 .

17. Breckenridge, A., and M. Orme. 1973. Studies of the kinetics of warfarin absorption in man. Clin. Pharmacol. Ther. 14: 955.

18. Smith, J. N., R. H. Smithies, and R. T. Williams. 1954. Studies in detoxication: 59. The metabolism of alkylbenzenes. The biological reduction of ketones derived from alkylbenzenes. Biochem. J. 57: 74.

19. McMahon, R. E., F. J. Marshal, and H. W. Culp. 1965. The nature of the metabolites of acetohexamide in the rat and in the human. J. Pharmacol. Exp. Ther. 149: 272.

20. MacLeod, R., H. Prosser, L. Fikentscher, J. Lanyi, and H. S. Mosher. 1964. Asymmetric reductions. XII. Stereoselective ketone reductions by fermenting yeast. Biochemistry. 3: 838.

21. Chan, K. K., R. J. Lewis, and W. F. Trager. 1972. The absolute configurations of the four "warfarin" alcohols. J. Med. Chem. 15 : 1265.

22. Hewick, D. S., and J. McEwen. 1973. Plasma half-lives, plasma metabolites and anticoagulant efficacies of the enantiomers of warfarin in man. J. Pharm. Pharmacol. $25: 458$.

23. Goldstein, M., M. R. McKereghan, and E. Lauber. 1964. The stereospecificity of the enzymatic amphetamine $\beta$ hydroxylation. Biochim. Biophys. Acta. 89: 191.

24. Keberle, H., K. Hoffman, and K. Bernhard. 1962. The metabolism of glutethimide (doriden). Experientia (Basel). 18: 105.

25. Palmer, K. H., M. S. Fowler, and M. E. Wall. 1970. Metabolism of optically active barbiturates. II. S(-)pentobarbital. J. Pharmacol. Exp. Ther. 175: 38.

26. Palmer, K. H., M. S. Fowler, M. E. Wall, L. S. Rhodes, W. J. Waddell, and B. Baggett. 1969. The metabolism of $\mathrm{R}(+)$ - and RS-pentobarbital. J. Pharmacol. Exp. Ther. 170: 355.

27. Lewis, R. J., W. F. Trager, A. J. Robinson, and K. K. Chan. 1973. Warfarin metabolites: the anticoagulant activity and pharmacology of warfarin alcohols. $J$. Lab. Clin. Med. $81: 925$.

28. Cho, A. K., B. J. Hodshon, and B. B. Brodie. 1970. Effects of phenylbutazone on liver microsomal demethylase. Biochem. Pharmacol. 19 : 1817.

29. Christensen, L. K., J. M. Hansen, and M. Kristensen. 1963. Sulphaphenazole-induced hypoglycaemic attacks in tolbutamide-treated diabetics. Lancet. 2: 1298.

30. Chen, W., P. A. Vrindten, P. G. Dayton, P. Blaber, and J. J. Burns. 1962. Accelerated aminopyrine metabolism in human subjects pretreated with phenylbutazone. Life Sci. 1: 35 .

31. Kato, R., E. Chiesara, and P. Vassanelli. 1964. Further studies on the inhibition and stimulation of microsomal drug-metabolizing enzymes of rat liver by various compounds. Biochem. Pharmacol. 13: 69.

1616 Lewis, Trager, Chan, Breckenridge, Orme, Roland, and Schary 
32. Yü, T. F., P. G. Dayton, and A. B. Gutman. 1963. Mutual suppression of the uricosuric effects of sulfinpyrazone and salicylate: a study in interactions between drugs. J. Clin. Invest. $42: 1330$.

33. Field, J. B., M. Ohta, C. Boyle, and A. Remer. 1967. Potentiation of acetohexamide hypoglycemia by phenylbutazone. N. Engl. J. Med. 277: 889.

34. Solomon, H. M., and J. J. Schrogie. 1967. The effect of various drugs on the binding of warfarin ${ }^{14} \mathrm{C}$ to human albumin. Biochem. Pharmacol. 16: 1219.
35. Aggeler, P. M., R. A. O'Reilly, L. Leong, and P. E. Kowitz. 1967. Potentiation of anticoagulant effect of warfarin by phenylbutazone. N. Engl. J. Med. 276: 496.

36. O'Reilly, R. A., and P. M. Aggeler. 1968. Phenylbutazone potentiation of anticoagulant effect: fluorometric assay of warfarin. Proc. Soc. Exp. Biol. Med. 128: 1080

37. O'Reilly, R. A., M. A. Sahud, and A. J. Robinson. 1972. Studies on the interaction of warfarin and clofibrate in man. Thromb. Diath. Haemorrh. 27: 309. 